\title{
BMJ Open Cross-sectional assessment of patient attitudes towards participation in clinical trials: does making results publicly available matter?
}

\author{
Christopher W Jones, ${ }^{1}$ Valerie A Braz, ${ }^{1}$ Stephen M McBride, ${ }^{1}$ Brian W Roberts, ${ }^{1}$ \\ Timothy F Platts-Mills ${ }^{2}$
}

To cite: Jones CW, Braz VA, McBride SM, et al. Crosssectional assessment of patient attitudes towards participation in clinical trials: does making results publicly available matter?. BMJ Open 2016;6: 013649 .

doi:10.1136/bmjopen-2016013649

- Prepublication history and additional material is available. To view please visit the journal (http://dx.doi.org/ 10.1136/bmjopen-2016013649).

Received 27 July 2016 Revised 1 November 2016 Accepted 3 November 2016

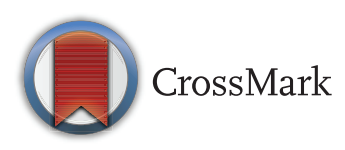

${ }^{1}$ Department of Emergency Medicine, Cooper Medical School of Rowan University, Camden, New Jersey, USA

${ }^{2}$ Department of Emergency Medicine, University of North Carolina Chapel Hill, Chapel Hill, North Carolina, USA

\section{Correspondence to} Dr Christopher Jones; jones-christopher @cooperhealth.edu

\section{ABSTRACT}

Objectives: Previous studies have shown that a majority of patients cite altruistic motives, such as contributing to generalisable medical knowledge, as factors motivating clinical trial participation. We sought to examine the impact of making trial results publicly available on patients' willingness to participate in clinical research.

Design: Cross-sectional analysis using a questionnaire developed by a panel with expertise in publication bias, informed consent and survey design.

Setting: A single urban, academic emergency department (ED) in the Northeastern USA.

Participants: 799 ED patients.

Outcome Measures: We assessed (1) participants' attitudes towards clinical trial participation, and (2) the impact of whether study results would eventually be made publicly available or not on willingness to participate in a trial.

Results: Of 799 patients surveyed, 36\% (95\% Cl 32\% to $39 \%$ ) reported that they would generally like to participate in a trial, and another $50 \%(95 \% \mathrm{Cl} 47 \%$ to $54 \%$ ) reported that they would consider participation depending on study details. For the majority of participants, the publication of trial results was either important (36\%; $95 \% \mathrm{Cl} 33 \%$ to $40 \%$ ) or very important (48\%; $95 \%$ Cl $44 \%$ to $51 \%)$. Most (63\%; $95 \% \mathrm{Cl} 59 \%$ to $66 \%$ ) reported they would be less likely to participate in a trial if investigators had not publicly released results from a prior study.

Additionally, $85 \%$ ( $95 \% \mathrm{Cl} 82 \%$ to $87 \%$ ) felt that it was important or very important to receive information about the publication track record of sponsors and investigators during the informed consent process.

Conclusions: The majority of patients in this sample would consider participation in a clinical trial. Patients value the public release of trial results, and believe that the informed consent process should address the possibility of non-publication.

\section{INTRODUCTION}

Clinical trials are critical to the advancement of medical knowledge. The vast majority of

\section{Strengths and limitations of this study}

- This study is unique in that it offers insight into the problem of non-publication from the perspective of research participants.

- The study used a pilot phase, recruited patients via random time block sampling, and assessed test-retest reliability in order to limit study bias.

- This is a single-centre study involving an urban emergency department in the USA; results may not be applicable to other patient populations.

- The results from this cross-sectional study are subject to selection bias.

trials involve an informed consent process, in which investigators inform potential participants about the anticipated risks and possible benefits of taking part in a trial and ensure that those patients who participate do so willingly. ${ }^{1}$ The informed consent process has evolved over the past several decades to better ensure patient autonomy. Continuing to identify what information potential participants feel is important to disclose during the informed consent process is of the utmost importance to ensure that patients can make a truly informed decision about participation in clinical trials.

Previous studies have found that a large proportion of patients cite altruistic motives, such as potential benefit to others and contributing to generalisable medical knowledge, as motivating factors to participate in a clinical trial. ${ }^{2-6}$ However, many clinical trials are never published: an estimated $50 \%$ of all clinical trials are not published and almost a third of trials involving more than 500 participants are not published. ${ }^{7-12}$ Several clinical trial registries, including ClinicalTrials.gov, now have results databases which allow investigators to share trial results independent of publication. However, only a minority of 
unpublished trials utilise these resources, and peerreviewed publication remains the primary way by which trial results are made available to the scientific community. ${ }^{8} 13$ Non-publication therefore greatly limits the potential of a trial to benefit others or increase medical knowledge.

It is unknown whether potential research participants are aware that failure to publicly release trial data is a problem, whether the release of trial results is important to potential study participants, and whether awareness of the possibility of non-publication might influence decisions about trial participation. The primary objective of this investigation was to examine how the possibility of non-publication might influence attitudes towards trial participation.

\section{MATERIALS AND METHODS}

This study was performed from January to April 2015 at Cooper University Hospital, an urban, academic emergency department (ED) serving a socioeconomically diverse community in the Northeastern USA. Eligible participants were English speaking and at least 18 years. Patients were excluded if they had an abnormal mental status, an acute psychiatric emergency or were critically ill, as defined by an emergency severity index (ESI) score of 1. Patients evaluated in our department's 'fast track' were also excluded, as these patients are often discharged rapidly, before consent for participation and completion of data collection can be performed.

We modified a previously published survey assessing reasons for trial participation. ${ }^{3}$ Construct validity of the modified survey was ensured through an iterative process of expert panel review, feedback and revision. This panel included members with expertise in publication bias, the informed consent process, research ethics and survey design. The completed instrument was piloted on 20 participants; no substantive changes were made following this pilot phase. The new survey consisted of questions assessing factors motivating participation in clinical research and opinions regarding the informed consent process.

Research assistants received their initial training on the study protocol during a didactic lecture session. An investigator then observed each research assistant and provided feedback on their interactions with enrolled participants until the research assistants each demonstrated proficiency with screening participants, obtaining informed consent and performing data collection.

Research assistants screened and enrolled participants using random time block sampling, in which screening occurred during randomly selected 2-hour blocks between 9:00 and 22:00, 7 days per week. We used random time block sampling in order to minimise sampling bias due to convenience sampling and to obtain a broad sample of participants, given limited resources available for data collection. Test-retest reliability was assessed among the first 50 participants who were admitted to the hospital and were therefore available for reassessment between 24 and 72 hours after their initial enrolment. These participants were administered a second survey which mirrored the first, but with changes in the exact syntax and order of the included questions. Initial and subsequent responses were then compared to assess the stability of responses to survey questions.

All data were entered into Research Electronic Data Capture (REDCap), a secure, web-based application designed to support data capture for research studies, and exported into SPSS V.20.0 (IBM Corp, Armonk, New York, USA) for analysis. ${ }^{14}$ We calculated descriptive statistics for the collected survey data. The $\chi^{2}$ test was used to compare responses among four predefined sociodemographic groups: sex, age ( $\geq 65$ vs $18-64$ ), race (whites vs Caucasians) and formal education (college degree vs no college degree). Missing data were excluded on a pairwise basis. $p$ Values of $<0.05$ were considered statistically significant. The Cooper University Hospital Institutional Review Board (IRB) approved the study protocol with verbal consent.

\section{RESULTS}

A total of 3509 patients were screened, of which 1691 were eligible for participation, and $799(47 \%)$ agreed to participate (figure 1). The study sample was diverse in regard to race and formal education; $16 \%$ had previously participated in a clinical research study (table 1). Forty-six per cent of study participants were discharged home following their ED evaluation, $18 \%$ were placed in observation status and $35 \%$ were admitted to the hospital.

Study participants largely recognised the key role that clinical trials play in making medical progress, with 95\% (95\% CI $93 \%$ to $96 \%$ ) describing clinical trials as being either important or very important in the advancement of medical treatments. Among those surveyed, 286 (36\%; $95 \%$ CI $32 \%$ to $39 \%$ ) reported that they would generally like to participate in a trial, and $401 \quad(50 \%$; $95 \%$ CI $47 \%$ to $54 \%$ ) reported that they would consider

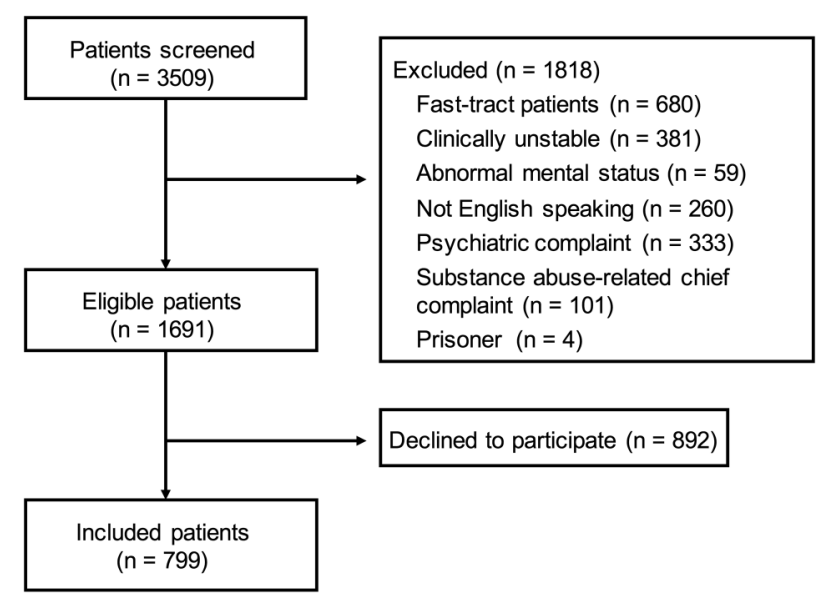

Figure 1 Flow chart of eligible patients. 
Table 1 Characteristics of study participants

\begin{tabular}{lc}
\hline Characteristic & $\begin{array}{c}\text { Participants } \\
(\mathbf{n}=799)\end{array}$ \\
\hline Age, mean (SD) & $50(17)$ \\
Female sex, $\mathrm{n}(\%)$ & $468(59)$ \\
Race, $\mathrm{n}(\%)^{*}$ & \\
White & $405(51)$ \\
Black & $259(32)$ \\
Asian & $14(2)$ \\
Other & $124(14)$ \\
Highest level of education, $\mathrm{n}(\%)$ & \\
Some high school or high school graduate & $389(49)$ \\
Some college & $176(22)$ \\
College graduate & $160(20)$ \\
Advanced degree & $51(6)$ \\
Unknown & $23(3)$ \\
Previous participation in a clinical research & $131(16)$ \\
study, $\mathrm{n}(\%)$ & \\
\hline${ }^{*}$ Respondents could select more than one answer.
\end{tabular}

participation depending on the details of the study (table 2).

Patients reported they would be strongly motivated to participate in clinical trials in order to establish or maintain a good relationship with their treating physician and in order to facilitate close monitoring of their own health (table 3). Additionally, $85 \%$ (95\% CI $83 \%$ to $88 \%$ ) of patients considered the possibility of benefit to future patients to be an important or very important factor motivating trial participation. Access to experimental interventions and reimbursement for participation were regarded as less influential factors in determining trial participation.

For most participants, the public release of trial results was either important $(36 \%)$ or very important $(48 \%)$ (table 4). Participants underestimated typical delays between trial completion and release of results (median estimate 12 months (IQR 6-18)), and estimated rates of failure to release results varied widely (mean 51\%, SD $27 \%)$. Sixty-three per cent $(95 \%$ CI $59 \%$ to $66 \%$ ) would be less likely to participate in a trial if investigators had not publicly released prior study results. Additionally, $85 \%(95 \%$ CI $82 \%$ to $87 \%)$ felt that receiving information about the publication track record of sponsors and investigators during the informed consent process was important or very important.

Views on trial participation remained largely stable among the participants evaluated in the ED and again during their hospital admission. Within this group of 50 participants, $46 \%(95 \%$ CI $32 \%$ to $60 \%)$ had a positive attitude towards trial participation when approached in the ED and $40 \%$ (95\% CI 26\% to $54 \%$ ) had a positive attitude towards trial participation when reapproached during their hospitalisation. Attitudes towards specific factors motivating participation also remained generally stable (see online supplementary appendix).
Table 2 General attitudes towards clinical trials

\begin{tabular}{|c|c|c|}
\hline Question & Answer choices & $\mathbf{N}(\%)$ \\
\hline \multirow{6}{*}{$\begin{array}{l}\text { What is your general } \\
\text { attitude towards clinical } \\
\text { trials? }\end{array}$} & Very positive & $167(21)$ \\
\hline & Positive & $300(38)$ \\
\hline & $\begin{array}{l}\text { Positive with } \\
\text { reservations }\end{array}$ & $178(22)$ \\
\hline & $\begin{array}{l}\text { Generally negative, } \\
\text { but realise necessity }\end{array}$ & $43(5)$ \\
\hline & Negative & $25(3)$ \\
\hline & No opinion & $86(11)$ \\
\hline \multirow{3}{*}{$\begin{array}{l}\text { What is your general } \\
\text { attitude towards } \\
\text { personally participating } \\
\text { in a clinical trial? }\end{array}$} & $\begin{array}{l}\text { Positive-would } \\
\text { generally like to } \\
\text { participate }\end{array}$ & $286(36)$ \\
\hline & $\begin{array}{l}\text { Neutral-would } \\
\text { depend on the study } \\
\text { details }\end{array}$ & $401(50)$ \\
\hline & $\begin{array}{l}\text { Negative-would } \\
\text { generally not want to } \\
\text { participate }\end{array}$ & $112(14)$ \\
\hline \multirow{4}{*}{$\begin{array}{l}\text { How important do you } \\
\text { think clinical trials are to } \\
\text { making advances in } \\
\text { medical treatments? }\end{array}$} & Very important & $539(68)$ \\
\hline & Important & 217 (27) \\
\hline & Minor importance & $23(3)$ \\
\hline & Not important & $19(2)$ \\
\hline
\end{tabular}

There were no significant differences in attitudes towards clinical trials or willingness to participate in a trial by patient gender or age $\geq 65$ years. Whites were more likely than non-whites to have a very positive or positive attitude towards trials in general $(64 \%$ vs $53 \%$, $\mathrm{p}<0.001)$ and more likely to have a positive or neutral attitude towards personal participation in a trial than non-whites $(89 \%$ vs $83 \% ; \mathrm{p}=0.03)$. Participants with a college degree were also more likely to view trials very positively or positively than participants who had not graduated from college ( $64 \%$ vs $56 \%, \mathrm{p}<0.01)$.

\section{DISCUSSION}

Numerous prior investigations have shown that approximately one-third to one-half of completed clinical trials never have results published in a peer-reviewed journal. ${ }^{7-9} 1516$ Failure to publicly release clinical trial results is a major threat to the validity of the medical literature, and addressing this problem is an active area of policy effort nationally and internationally. ${ }^{17-19}$ Although study participants often cite contributing to knowledge as a reason for participation in clinical trials, consent forms rarely if ever describe the potential that results might not be made publicly available. In this large study of attitudes among a diverse group of potential clinical trial participants, we observe that the majority of participants placed substantial value on the release of trial results. Specifically, we find that a majority of the participants in our study would be less likely to participate in a new trial if the investigators had not released 
Table 3 Factors influencing trial participation

\begin{tabular}{llr}
\hline Question: If you were asked about participation in a clinical trial and you & & N (\%) \\
accepted, what would the reason(s) for your acceptance be? & Answer choices & $274(34)$ \\
\hline The wish to get the 'new' drug & Very important & $309(39)$ \\
& Important & $133(17)$ \\
& Minor importance & $83(10)$ \\
The wish to help future patients by testing new drugs & Not important & $362(45)$ \\
& Very important & $321(40)$ \\
& Important & $57(7)$ \\
The wish to have your health monitored closely by study physicians and nurses & Minor importance & $59(7)$ \\
& Not important & $475(60)$ \\
The wish to have a good relationship with your treating physician & Important & $233(29)$ \\
& Minor importance & $54(7)$ \\
& Not important & $35(4)$ \\
Positive experiences from participation in other research studies & Very important & $509(64)$ \\
& Important & $217(27)$ \\
& Minor importance & $36(5)$ \\
& Not important & $37(5)$ \\
Payment for your time spent participating in the trial & Very important & $310(39)$ \\
& Important & $318(40)$ \\
& Minor importance & $61(8)$ \\
& Not important or not & $109(14)$ \\
& applicable & \\
& Very important & $217(27)$ \\
& Important & $227(28)$ \\
& Minor importance & $181(23)$ \\
& Not important & $174(22)$ \\
\hline
\end{tabular}

Table 4 Patient attitudes towards the making trial results publically available

\begin{tabular}{llr}
\hline Question & Answer choices & N (\%) \\
\hline If you knew that a study sponsor or investigator had not made results & More likely to participate & $96(12)$ \\
from previous trials publicly available, would this affect your decision to & Less likely to participate & $499(63)$ \\
participate in a new trial run by the same group? & No impact & $204(26)$ \\
How important is it to you that the people who did the study make the & Very important & $383(48)$ \\
results from a trial that you took part in publicly available? & Important & $291(36)$ \\
& Minor importance & $78(10)$ \\
How important is it to you that the people who did the study make the & Not important & $47(6)$ \\
results from a trial that you took part in available to you personally? & Very important & $413(52)$ \\
& Important & $264(33)$ \\
As part of the informed consent process, how important would it be to & Minor importance & $69(9)$ \\
you as a potential trial participant to know whether the people & Not important & $52(7)$ \\
sponsoring or running the trial had made the results from previous trials & Important & $385(48)$ \\
available to the public? & Minor importance & $290(36)$ \\
\hline
\end{tabular}

results from a previous clinical trial, and a majority felt that the publication track records of investigators and sponsors should be disclosed during the informed consent process.

Clinical trial registries were developed in part to make it easier for the scientific community to identify, track and obtain results from unpublished trials. ${ }^{20}$ Additionally, registries have the potential to improve awareness among prospective and actual trial participants with respect to the prior publication track records of investigators and sponsors, and they also provide trial participants with the a mechanism to track the publication status of the trial in which they took part. To this end, in order to comply with the Food and Drug Amendments Act of 2006 (FDAAA), applicable clinical trials initiated on or after 7 March 2012 have been required to include the following language in informed consent documents: 'A description of this clinical trial will be available on 
http://www.ClinicalTrials.gov, as required by U.S. Law. This Web site will not include information that can identify you. At most, the Web site will include a summary of the results. You can search this Web site at any time'. ${ }^{21}$ However, the impact of this policy is likely limited. First, many trials do not meet the FDAAA definition of an 'applicable clinical trial', and therefore, investigators are not required to inform potential participants about the trial's registration status in the first place ${ }^{22}{ }^{23}$ Second, as with other aspects of the FDAAA, the capacity for enforcement of this aspect of the law is limited and the degree to which study sponsors comply is unknown. Finally, although use of this language in the consent may raise awareness of trial registration among participants in applicable clinical trials, identifying a specific trial within ClinicalTrials.gov often requires a relatively high degree of scientific literacy, and many trial participants may not be able to identify the registry entry for their specific trial based on the information available to them.

IRBs are responsible for protecting the interests of human research participants. ${ }^{24}$ Our results identify the public release of trial results as an explicitly stated interest of study participants, and raise the question of how best to ensure that this interest is protected. Several possible changes in the current approach to informed consent could address this challenge. First, in the case of applicable trials under the FDAAA, the unique trial identifier number assigned to each individual trial could be included in the consent form in order to facilitate identification of the trial's specific registry entry. Second, local IRBs should consider requiring all trials, even those that do not meet FDAAA criteria as applicable clinical trials, to report their registration status and registry identification number to prospective participants. Third, although most investigators cannot anticipate non-publication, some information might be presented in the consent process regarding the publication of results. For FDAAA eligible studies, availability of study results within 1 year of study completion is required by law unless the responsible party obtains an extension, but compliance with this requirement is poor. ${ }^{23}$ For all studies, the investigator's and the sponsor's track record of making results public could be included in the consent. Importantly, these proposed changes to the informed consent process have the potential to cause unintended consequences, and the effects on decision-making among prospective trial participants as well as patient accrual should be studied. Additionally, it may be challenging to find the ideal balance between providing enough information to inform enrolment decisions while avoiding the introduction of unnecessary complexity into the informed consent process. Collectively, however, these changes might help study participants make more informed decisions regarding participation and increase pressure on investigators and sponsors to make results of clinical trials publicly available.

\section{Limitations}

Several limitations should be considered when interpreting these results. First, this study was performed in the ED of a single urban, academic medical centre located in the Northeastern USA. The population sampled in this study may be quite different from the target population for some clinical trials. In particular, these results may not apply to phase I trials, which involve healthy volunteers rather than patients. However, EDs provide access to a racially and socioeconomically diverse population and are often used to recruit patients for interventional studies involving patients with acute injuries or illnesses. Second, 53\% of otherwise eligible patients refused to participate. For some, refusal likely reflects the symptom burden and time constraints faced by patients receiving care in the ED. For others, refusal likely reflects a lack of interest in contributing to the study. While this somewhat limits the generalisability of these data, the patients who declined to participate in the present study are also probably less likely to participate in a clinical trial and so their answers would be less relevant than answers from those patients who were willing to participate. Third, it is possible that the act of asking participants to answer questions regarding the release of trial data may have influenced their stated views on the topic. Participants may not have recognised the failure to release trial results as a potential problem prior to being asked about it, or their opinions about the importance of non-publication may have changed as a result of participating in the study. Finally, we asked patients questions about participation in a hypothetical study; answers given under these circumstances might not accurately reflect behaviour when faced with the choice of actually participating in a specific trial for an active medical problem.

\section{CONCLUSIONS}

The desire to contribute to generalisable medical knowledge is a strong motivating factor for research participants. Participants place substantial value on the public release of trial results, and believe that the informed consent process should address the possibility of non-publication.

Contributors CWJ conceived the study idea, performed data analysis, and drafted the manuscript. CWJ, VAB, BWR, and TFP-M designed the study. SMM and VAB performed data collection. All authors contributed to critical revision of the manuscript. All authors read and approved the final manuscript.

Funding This research received no specific grant from any funding agency in the public, commercial or not-for-profit sectors.

Competing interests CWJ is an investigator on studies sponsored by Janssen, Astra Zeneca and Roche Diagnostics.

Ethics approval Cooper Hospital Institutional Review Board.

Provenance and peer review Not commissioned; externally peer reviewed.

Data sharing statement Requests for access to the complete data set may be sent to the corresponding author CWJ at jones-christopher@cooperhealth.edu. 
Open Access This is an Open Access article distributed in accordance with the Creative Commons Attribution Non Commercial (CC BY-NC 4.0) license, which permits others to distribute, remix, adapt, build upon this work noncommercially, and license their derivative works on different terms, provided the original work is properly cited and the use is non-commercial. See: http:// creativecommons.org/licenses/by-nc/4.0/

\section{REFERENCES}

1. Moreno J, Caplan AL, Wolpe PR. Updating protections for human subjects involved in research. Project on Informed Consent, Human Research Ethics Group. JAMA 1998;280:1951-8.

2. Cassileth BR, Lusk EJ, Miller DS, et al. Attitudes toward clinical trials among patients and the public. JAMA 1982;248:968-70.

3. Madsen S, Holm S, Riis P. Ethical aspects of clinical trials: the attitudes of the public and out-patients. J Intern Med 1999;245 571-9.

4. Madsen SM. [Attitudes toward and experiences with clinical research among current and potential research subjects]. Ugeskr Laeg 2004; 166:2343-4

5. Moorcraft SY, Marriott C, Peckitt C, et al. Patients' willingness to participate in clinical trials and their views on aspects of cancer research: results of a prospective patient survey. Trials 2016;17:17.

6. McCann SK, Campbell MK, Entwistle VA. Reasons for participating in randomised controlled trials: conditional altruism and considerations for self. Trials 2010;11:31.

7. Gordon D, Taddei-Peters W, Mascette A, et al. Publication of trials funded by the National Heart, Lung, and Blood Institute. N Engl J Med 2013;369:1926-34.

8. Jones CW, Handler L, Crowell KE, et al. Non-publication of large randomized clinical trials: cross sectional analysis. BMJ 2013;347: f6104.

9. Ross JS, Mulvey GK, Hines EM, et al. Trial publication after registration in ClinicalTrials.Gov: a cross-sectional analysis. PLOS Med 2009;6:e1000144.

10. Decullier E, Lhéritier V, Chapuis F. Fate of biomedical research protocols and publication bias in France: retrospective cohort study. BMJ 2005;331:19.

11. Callaham ML, Wears RL, Weber EJ, et al. Positive-outcome bias and other limitations in the outcome of research abstracts submitted to a scientific meeting. JAMA 1998;280:254-7.

12. Schmucker $C$, Schell LK, Portalupi $S$, et al. Extent of non-publication in cohorts of studies approved by research ethics committees or included in trial registries. PLOS ONE 2014;9:e114023.
13. Chen R, Desai NR, Ross JS, et al. Publication and reporting of clinical trial results: cross sectional analysis across academic medical centers. BMJ 2016;352:i637.

14. Harris PA, Taylor R, Thielke R, et al. Research electronic data capture (REDCap) - a metadata-driven methodology and workflow process for providing translational research informatics support. $J$ Biomed Inform 2009:42:377-81.

15. Bourgeois FT, Murthy $\mathrm{S}$, Mandl KD. Outcome reporting among drug trials registered in ClinicalTrials.gov. Ann Intern Med 2010;153:158-66.

16. Riveros C, Dechartres A, Perrodeau E, et al. Timing and completeness of trial results posted at ClinicalTrials.gov and published in journals. PLoS Med 2013;10:e1001566; discussion e1001566.

17. Department of Health and Human Services. National Institutes of Health. Announcement of a Draft NIH Policy on Dissemination of NIH-Funded Clinical Trial Information. Vol. 80. Federal Register, 2015:80896.

18. Moorthy VS, Karam G, Vannice KS, et al. Rationale for WHO's new position calling for prompt reporting and public disclosure of interventional clinical trial results. PLoS Med 2015;12: e1001819.

19. Meerpohl JJ, Schell LK, Bassler D, et al. Evidence-informed recommendations to reduce dissemination bias in clinical research: conclusions from the OPEN (Overcome failure to Publish nEgative fiNdings) project based on an international consensus meeting. $B M J$ Open 2015;5:e006666.

20. De Angelis C, Drazen JM, Frizelle FA, et al. Clinical trial registration: a statement from the International Committee of Medical Journal Editors. N Engl J Med 2004;351:1250-1.

21. US Department of Health and Human Services Food and Drug Administration. Guidance for Sponsors, Investigators, and Institutional Review Boards: Questions and Answers on Informed Consent Elements, 21 CFR 50.25(c). http://www.fda.gov/downloads/ RegulatoryInformation/Guidances/UCM291085.pdf (accessed 28 Dec 2015).

22. US National Institutes of Health. FDAAA 801 Requirements https:// clinicaltrials.gov/ct2/manage-recs/fdaaa. Updated November 2015 (accessed 28 Dec 2015).

23. Anderson ML, Chiswell K, Peterson ED, et al. Compliance with results reporting at ClinicalTrials.gov. $N$ Engl $J$ Med 2015;372:1031-9.

24. World Medical Association. Declaration of Helsinki: ethical principles for medical research involving human subjects. WMA General Assembly: 1-8. http://www.wma.net/en/30publications/10policies/b3/. Updated October 2013 (accessed 28 Dec 2015). 